\title{
Rectal Tubular Adenoma
}

National Cancer Institute

\section{Source}

National Cancer Institute. Rectal Tubular Adenoma. NCI Thesaurus. Code C96477.

A usually polypoid neoplasm that arises from the glandular epithelium of the rectal mucosa. It is characterized by a tubular architectural pattern. The neoplastic glandular cells have dysplastic features. 